\title{
Interleukin-21 promotes osteoclastogenesis in RAW264.7 cells through the PI3K/AKT signaling pathway independently of RANKL
}

\author{
RUI XING ${ }^{*}$, YINGJIAN ZHANG ${ }^{*}$, CHANGHONG LI, LIN SUN, LIN YANG, JINXIA ZHAO and XIANGYUAN LIU \\ Department of Rheumatology and Immunology, Peking University Third Hospital, Beijing 100191, P.R. China
}

Received July 30, 2015; Accepted August 26, 2016

DOI: $10.3892 /$ ijmm.2016.2722

\begin{abstract}
Cytokines play a key role in the bone destruction of rheumatoid arthritis (RA). Interleukin-21 (IL-21) promotes osteoclastogenesis in RA in a receptor activator of nuclear factor- $\kappa \mathrm{B}$ ligand (RANKL)-dependent way. Whether IL-21 is capable of promoting osteoclastogenesis directly in the absence of RANKL remains unknown. In the present study, we examined the osteoclastogenic activity of IL-21 in RAW264.7 cells in the absence of RANKL. We found that IL-21 enhanced osteoclastogenesis and this was demonstrated by increased numbers of tartrate-resistant acid phosphatase (TRAP)-positive stained, multinucleated cells compared with the negative control. Western blot analysis and immunocytochemistry showed the positive expression of calcitonin receptor (CTR) in the IL-21 group. RT-PCR and RT-qPCR also verified the increased mRNA expression of CTR and cathepsin $\mathrm{K}$ in the IL-21 group compared with the negative control. The scanning electronic microscope images showed a few resorption pits on the bone slices cultured with IL-21. The phosphoinositide 3-kinase (PI3K)/AKT pathway inhibitor LY294002 significantly suppressed IL-21-induced osteoclastogenesis. Taken together, these findings suggest that IL-21 has direct osteoclastogenic potential independently of RANKL. IL-21 may promote osteoclastogenesis through the PI3K/AKT signaling pathway. Therapy targeting IL-21 may be of value in preventing bone erosions in patients with RA.
\end{abstract}

Correspondence to: Professor Jinxia Zhao or Professor Xiangyuan Liu, Department of Rheumatology and Immunology, Peking University Third Hospital, 49 North Garden Road, Beijing 100191, P.R. China E-mail: zhao-jinxia@163.com

E-mail: liu-xiangyuan@263.net

*Contributed equally

Abbreviations: M-CSF, macrophage colony-stimulating factor; RANK, receptor activator of NF- $\mathrm{B}$; TRAP, tartrate-resistant acid phosphatase

Key words: rheumatoid arthritis, interleukin-21, osteoclastogenesis, AKT, RAW264.7 cells

\section{Introduction}

Rheumatoid arthritis (RA) is a systemic autoimmune disease characterized by chronic synovitis and bone erosions. The massive infiltration of inflammatory cells as well as multiple cytokines in the synovium contribute to the progression of synovitis, which plays a key role in the destruction of bone. Osteoclast formation and differentiation have been described in the inflamed synovial membrane, where they derive from precursors of the monocyte/macrophage lineage (1). Macrophages are central effectors of synovitis, mainly acting through the release of cytokines [such as tumor necrosis factor- $\alpha$ (TNF)- $\alpha$ and interleukin (IL)-1 and IL-6] to induce osteoclastogenesis (2). Some proinflammatory cytokines, such as TNF- $\alpha$, or IL- $1 \beta$ provided by activated $\mathrm{CD} 4^{+} \mathrm{T}$ cells and synoviocytes may induce osteoclastogenesis directly or act indirectly on osteoclastogenesis by enhancing the release of receptor activator of nuclear factor- $\kappa B$ ligand (RANKL) from other cells $(3,4)$. Agents capable of regulating these proinflammatory cytokines may prevent disease progression, and are therefore suitable candidates for use in the treatment of RA.

IL-21 is a recently discovered cytokine produced by activated $\mathrm{CD}^{+} \mathrm{T}$ lymphocytes and follicular helper $\mathrm{T}$ (Tfh) cells $(5,6)$. Functional IL-21 receptor (IL-21R) is broadly expressed on immune cells and some non-immune cells including fibroblasts and epithelial cells (7). One study showed that the $\mathrm{CD}^{+} \mathrm{T}$ cells of patients with RA expressed significantly higher levels of IL-21R than those from patients with osteoarthritis (8). Correspondingly, IL-21 exerts pleiotropic effects on a broad range of cell types; IL-21 regulates the proliferation of $\mathrm{T}$ cells, the proliferation and differentiation of $\mathrm{B}$ cells, and the activation and expansion of natural killer cells (9). It also promotes the secretion of matrix metalloproteinases in fibroblasts (10). It has been demonstrated that IL-21 may play a role in many autoimmune diseases, including RA (9).

Serum levels of IL-21 and IL-23 positively correlate with disease activity and radiologic changes in RA (11). The blockade of IL-21 signaling pathways with an IL-21R Fc fusion protein (IL-21R.Fc) reduces the production of inflammatory cytokines and attenuates the progression of arthritis in animal models of collagen-induced arthritis (CIA) (12). It has been demonstrated that IL-21 enhances RANKL expression in CD4 ${ }^{+}$ $\mathrm{T}$ cells and fibroblast-like synoviocytes (FLSs) from patients with RA, and IL-21 has osteoclastogenic potential in the 
presence of low dose RANKL and macrophage colony-stimulating factor (M-CSF), both in humans with RA and in mice with CIA (13). These results show that IL-21 may play a role in synovitis and bone erosion in RA.

It remains unclear whether IL-21 promotes osteoclastogenesis directly in the absence of RANKL. To determine the direct effect of IL-21 on osteoclastogenesis, we evaluated the osteoclastogenic potential of IL-21 on RAW264.7 cells, using tartrate-resistant acid phosphatase (TRAP) staining for osteoclasts and quantitative assays to measure the expression of osteoclastic markers. The results demonstrated that IL-21 induces the osteoclastogenesis of RAW264.7 cells independently of RANKL through the phosphatidylinositol 3-kinase (PI3K)/AKT signaling pathway. IL-21 also showed osteogenic potency in the peripheral blood mononuclear cells (PBMCs) isolated from patients with RA. Taken together, these findings suggest that IL-21 may be a novel therapeutic target for the treatment of RA.

\section{Materials and methods}

Antibodies and reagents. Phycoerythrin-conjugated rat monoclonal anti-mouse RANK antibody (12-6612) and the isotypic antibody, phycoerythrin-conjugated rat $\operatorname{IgG} 2 \mathrm{~b}$ (15-4815), were purchased from eBioscience, Inc. (San Diego, CA, USA). Anti-phospho-AKT (Ser473) (9271), anti-AKT (9272), anti-phospho-p44/42 ERK (Thr202/Tyr204) (4370), anti-ERK (4695), and anti-signal transducer and activator of transcription 3 (STAT3) (4904) antibodies were obtained from Cell Signaling Technology, Inc. (Beverly, MA, USA). The antibody against mouse phospho-STAT3 (Ser727) (sc-135649) was purchased from Santa Cruz Biotechnology, Inc. (Santa Cruz, CA, USA). Anti-RANK (ab200369), anti-calcitonin receptor (CTR) (ab11042) and anti-IL-21R (ab5980) and anti- $\beta$-actin (ab8229) antibodies were obtained from Abcam (Cambridge, UK). Horseradish peroxidase-conjugated secondary antibodies were purchased from LI-COR Biosciences (Lincoln, Nebraska, USA). Recombinant IL-21, RANKL and M-CSF were obtained from Peprotech, Inc. (Rocky Hill, NJ, USA). AG490 [Janus kinase 2 (JAK2)/STAT3 inhibitor], LY294002 (PI3K/AKT inhibitor), and PD98059 (ERK inhibitor) were supplied by Selleck Chemicals (Houston, TX, USA).

Induction of osteoclastogenesis by IL-21 in RAW264.7 cells. RAW264.7 cells, a murine macrophage cell line, were obtained from the Cell Center of Peking Union Medical College (Beijing, China). The cells were cultured in high-glucose Dulbecco's modified Eagle's medium (DMEM) supplemented with $10 \%(\mathrm{v} / \mathrm{v})$ inactivated fetal bovine serum (FBS), $100 \mathrm{U} / \mathrm{ml}$ penicillin and $100 \mu \mathrm{g} / \mathrm{ml}$ streptomycin (all from Gibco, Grand Island, NY, USA) in a $37^{\circ} \mathrm{C}$ incubator containing a 5\% $\mathrm{CO}_{2}$-enriched atmosphere. The RAW264.7 cells were further cultured onto 24 -well plates $\left(5 \times 10^{4}\right.$ cells/well) in the presence of $5 \mathrm{ng} / \mathrm{ml}$ recombinant $\mathrm{M}-\mathrm{CSF}$, with or without $10 \mathrm{ng} / \mathrm{ml}$ soluble RANKL (sRANKL), or various concentrations of IL-21 $(0,1,10,20$ and $40 \mathrm{ng} / \mathrm{ml})$ for 5 days in order to generate osteoclasts. Osteoprotegerin (OPG; Peprotech, Rocky Hill, NJ, USA) (20 and $100 \mathrm{ng} / \mathrm{ml}$ ) was added to the culture with M-CSF and IL-21 to eliminate the osteoclastogenic effects of endogenous RANKL. Prior to the addition of IL-21 (20 ng/ml) into the culture, various signaling pathway inhibitors (AG490 $50 \mu \mathrm{M}, \mathrm{LY} 29400210 \mu \mathrm{M}$ and PD98059 $20 \mu \mathrm{M}$ ) were incubated with RAW264.7 cells for $30 \mathrm{~min}$. Osteoclast formation was determined after 5 days of culture. The phosphorylation of the signaling proteins was detected by western blot analysis precisely $0,5,15,30,45,60,90$ and 120 min after initiating stimulus with IL-21 $(20 \mathrm{ng} / \mathrm{ml})$.

TRAP staining. The RAW264.7 cells were plated at a density of $5 \times 10^{4}$ cells/well in 24 -well plates for $12 \mathrm{~h}$, and then treated with the indicated compounds for an additional 5 days. The supernatants were removed, and the cells were washed twice with phosphate-buffered saline (PBS). Paraformaldehyde (4\%) was added to the cells for $20 \mathrm{~min}$ at room temperature and then thoroughly removed with deionized water. Naphthol AS-BI phosphate and tartrate solution (Sigma-Aldrich, St Louis, MO, USA) were added to the cells for $30 \mathrm{~min}$ at $37^{\circ} \mathrm{C}$, followed by counterstaining with a hematoxylin solution (Sigma-Aldrich). Osteoclasts were determined to be TRAP-positively stained, multinucleated (three or more nuclei) cells and counted under a light microscope (original magnification, x100).

Immunocytochemistry. The RAW264.7 cells were cultured in 24-well plates in the presence of M-CSF, with or without sRANKL, or various concentrations of IL-21 for 5 days. The supernatants were removed, and the cells were fixed in paraformaldehyde (4\%) for $20 \mathrm{~min}$ at room temperature. The cells were depleted of endogenous peroxidase activity with $3 \% \mathrm{H}_{2} \mathrm{O}_{2}$ for 15 minutes, blocked with secondary antibody serum for $20 \mathrm{~min}$, and incubated with anti-CTR antibody at $4^{\circ} \mathrm{C}$ overnight. The samples were incubated with an HRP-conjugated secondary antibody at $37^{\circ} \mathrm{C}$ for 30 minutes followed by 3,3'-diaminobenzidine (Dako, Glostrup, Denmark). The cells were counterstained with haematoxylin, and the images of the samples were captured using a photomicroscope (original magnification, x100).

Reverse transcription-quantitative polymerase chain reaction $(R T-q P C R)$. Total RNA was isolated using TRIzol reagent (Invitrogen, Carlsbad, CA, USA) according to the manufacturer's instructions. Two micrograms of total RNA from each sample was reverse transcribed using Superscript II Reverse Transcriptase (Invitrogen). The reverse transcription reaction was performed at $42^{\circ} \mathrm{C}$ for $50 \mathrm{~min}$, and then at $70^{\circ} \mathrm{C}$ for $15 \mathrm{~min}$. PCR amplification was performed on a Bio-Rad iQ5 Real-Time PCR system (Berkely, CA, USA) using SYBR-Green dye (Promega Corp., Madison, WI, USA). The melting curve temperatures of each PCR gene were all $60^{\circ} \mathrm{C}$. The following primers were used: GAPDH forward, 5'-AAATGGTGAAGGTCGGTGTG-3' and reverse, 5'-TGAA GGGGTCGTTGATGG-3'; CTR forward, 5'-TGGCGACTAT CTACTGCTTCTG-3' and reverse, 5'-GTTGTTGCTGATTG GAGGATTC-3'; RANK forward, 5'-GTCTCATCGTTCTGCT CCTCTT-3' and reverse, 5'-AACTGCTTTTTGAGCCAG GAC-3'; and cathepsin $\mathrm{K}$ forward, 5'-GTTGTATGTATAACG CCACGGC-3' and reverse, 5'-CTTTCTCGTTCCCCACA GGA-3. The fold changes compared with the control were calculated using the formula $2^{-\Delta \Delta \mathrm{Ct}}$. 
Reverse transcription-polymerase chain reaction ( $R T-P C R)$. Total RNA was extracted from the cells using TRIzol reagent (Invitrogen) according to the manufacturer's instructions and $1 \mu \mathrm{g}$ of total RNA from each sample was reverse transcribed using Superscript II Reverse Transcriptase (Invitrogen). The reverse transcription reaction was performed at $42^{\circ} \mathrm{C}$ for $50 \mathrm{~min}$, and then at $70^{\circ} \mathrm{C}$ for $15 \mathrm{~min}$. PCR amplification was performed by denaturation at $94^{\circ} \mathrm{C}$ for $30 \mathrm{sec}$, annealing at $60^{\circ} \mathrm{C}$ for $30 \mathrm{sec}$, and extension at $72^{\circ} \mathrm{C}$ for $30 \mathrm{sec}$ using Takara Ex Taq (Takara Bio, Inc., Otsu, Japan). The amplified PCR products were separated on a $1.5 \%$ agarose gel. The following primers were used: IL-21R forward, 5'-GGCTGCCTTACTCCTGCTG-3' and reverse, 5'-TCATCTTGCCAGGTGAGACTG-3'; and TRAP forward, 5'-AACTTCCCCAGCCCTTACTACC-3' and reverse, 5'-AACTGCTTTTTGAGCCAGGAC-3'; The primer sequences for GAPDH, RANK, CTR and cathepsin K were the same as those used for RT-qPCR.

Western blot analysis. The RAW264.7 cells were lysed in protein extraction solution. The lysates were centrifuged at $12,000 \mathrm{x} \mathrm{g}$ for $15 \mathrm{~min}$ at $4^{\circ} \mathrm{C}$ to remove the cell debris. The protein concentration of the extract was determined using the BCA protein assay kit (Beijing ComWin Biotech Co., Ltd., Beijing, China). Equal amounts of protein were separated by $10 \%$ sodium dodecyl sulfate-polyacrylamide gel electrophoresis and transferred to polyvinylidene fluoride (PVDF) membranes (Immobilon-P; Millipore, Billerica, MA, USA) and blocked with 5\% skim milk in $0.05 \%$ Tween-20 and Tris-buffered saline (TBST) at room temperature for $2 \mathrm{~h}$. The membranes were then incubated with various primary antibodies, which were diluted in $5 \%$ bovine serum albumin (BSA)-TBST at $4^{\circ} \mathrm{C}$ with gentle shaking overnight. After washing, the membranes were incubated with a horseradish peroxidase-conjugated secondary antibody at room temperature for $1 \mathrm{~h}$. The blots were developed using an enhanced chemiluminescence detection kit (Pierce Biotechnology, Inc., Rockford, IL, USA).

Bone resorption analysis. The RAW264.7 macrophages prepared using the methods described above were cultured in 96-well plates with thin slices of femoral cow bone (Nordic Bioscience, Copenhagen, Denmark). The RAW264.7 cells were further cultured in the presence of $5 \mathrm{ng} / \mathrm{ml}$ recombinant M-CSF, with or without $10 \mathrm{ng} / \mathrm{ml}$ sRANKL, or IL-21 (20 ng/ml) in order to generate osteoclasts. After 7 days, the cells on the bone slice were removed, and the resorption pits on the bone slices were observed under a scanning electronic microscope (S-4800; Hitachi, Tokyo, Japan).

Induction of osteoclastogenesis by IL-21 in RA. The present study was approved by the Ethics Committee of Peking University Third Hospital (Beijing, China). Informed consent for the use of human mononuclear cells were obtained from all patients. Peripheral blood was obtained from 5 patients with RA (2 male, 3 female; mean age, 41.14 \pm 11.07 years). PBMCs were isolated from buffy coats by density-gradient centrifugation using Ficoll-Hypaque (Life Technologies, Grand Island, NY, USA). The cells were washed three times with sterile PBS and resuspended in RPMI-1640 (Life
Technologies) supplemented with $10 \%$ FBS, then seeded onto 24-well plates at a density of $1 \times 10^{6}$ cells/well and incubated at $37^{\circ} \mathrm{C}$ for $2 \mathrm{~h}$ to separate the floating and adherent cells. The adherent cells were washed with sterile PBS and cultured with M-CSF (50 ng/ml), M-CSF + RANKL (100 ng/ml), or various concentrations of IL-21 (0,1, 10, 50 and $100 \mathrm{ng} / \mathrm{ml})$. On day 7, TRAP-positive multinucleated cells were identified using an acid phosphatase kit (Sigma-Aldrich), according to the manufacturer's instructions. To examine the osteoclastogenetic effect of IL-21 in the presence of T lymphocytes, the floating cells were not removed when adding $\mathrm{M}-\mathrm{CSF}$ $(50 \mathrm{ng} / \mathrm{ml}), \mathrm{M}-\mathrm{CSF}+\mathrm{RANKL}(100 \mathrm{ng} / \mathrm{ml})$, or IL-21 $(0,1,10$, 50 and $100 \mathrm{ng} / \mathrm{ml}$ ) in order to generate osteoclasts.

Statistical analysis. Statistical analysis was performed using the SPSS 17.0 statistical software package (SPSS, Inc., Chicago, IL, USA) and GraphPad Prism 5.0 (GraphPad Software, Inc., San Diego, CA, USA). All quantitative data is expressed as the means \pm standard error of the mean (SEM) for each condition. For comparisons of multiple groups, a one-way analysis of variance (ANOVA) followed by a Scheffe's post hoc test was performed. P-values $<0.05$ were considered to indicate a statistically significant difference.

\section{Results}

IL-21 enhances RANK expression in RAW264.7 cells. RANK and RANKL are known to be the prototype mediators of osteoclastogenesis (14). A previous study has shown that IL-21 enhances RANKL expression in cultured mixed joint cells and $\mathrm{CD}^{+} \mathrm{T}$ cells from mice with CIA (13). Herein, we examined whether IL-21 induced the expression of RANK in RAW264.7 cells. As shown in Fig. 1A, the RT-PCR results showed that the mRNA expression of RANK was increased by stimulation with IL-21 (20 ng/ml). Western blot analysis confirmed that IL-21 upregulated the expression of RANK (Fig. 1B). We also examined whether IL-21 induced IL-21R expression in RAW264.7 cells. As shown in Fig. 1C and D, IL-21 had no significant effect on IL-21R expression.

IL-21 induces osteoclastogenesis in RAW264.7 cells directly. To examine whether IL-21 has osteoclastogenic potential without RANKL, RAW264.7 cells were stimulated with IL-21 and M-CSF, in the presence or absence of RANKL. The results showed that IL-21 induced osteoclastogenesis. As shown in Fig. 2, the IL-21 $10 \mathrm{ng} / \mathrm{ml}$ group (15.17 $\pm 3.79 /$ well, $\mathrm{P}<0.01)$ and $20 \mathrm{ng} / \mathrm{ml}$ group $(22 \pm 10.04 /$ well, $\mathrm{P}<0.01)$ showed osteoclast formation with more TRAP-positive cells than the negative control group $(1 \pm 1.32 /$ well). By contrast, IL-21 plus RANKL (14.67 $\pm 4.37 /$ well) did not show any advantages in promoting osteoclastogenesis compared with IL-21 $(22 \pm 10.04 /$ well, $\mathrm{P}=0.241)$ and RANKL $(16.33 \pm 4.8 /$ well, $\mathrm{P}>0.05$ ) single stimulation.

Immunocy tochemistry revealed higher positive expression of CTR in the IL-21 group (Fig. 3A) than in the control group. Western blot analysis showed (Fig. 3C) that RANKL markedly induced CTR expression. IL-21 induced a moderate effect on CTR expression compared with RANKL. Low dose IL-21 (1 ng/ml) stimulated the expression of CTR in a manner which was not dose-dependent. In the absence 
A
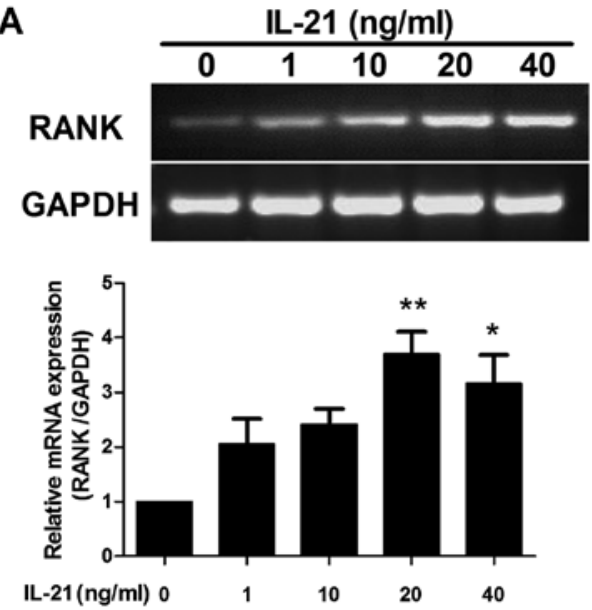

C
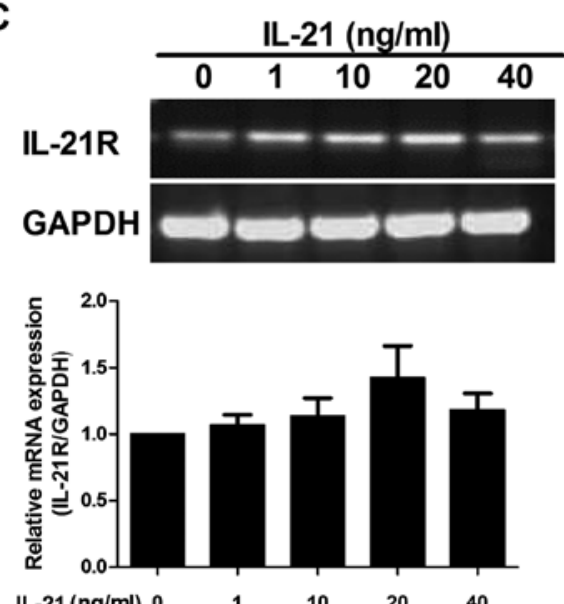

B
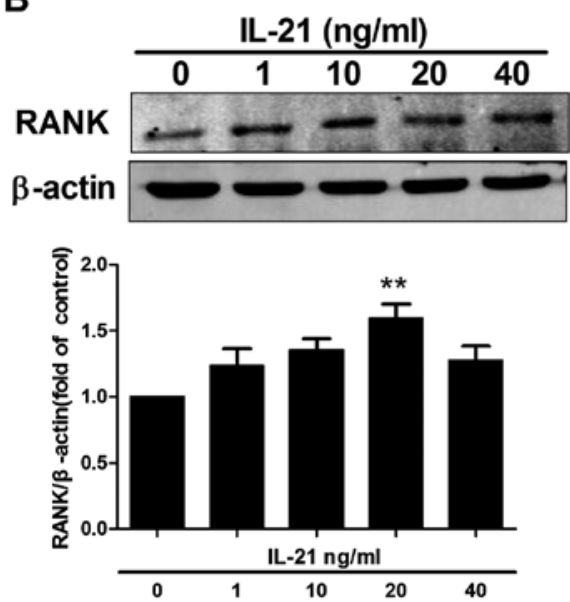

D
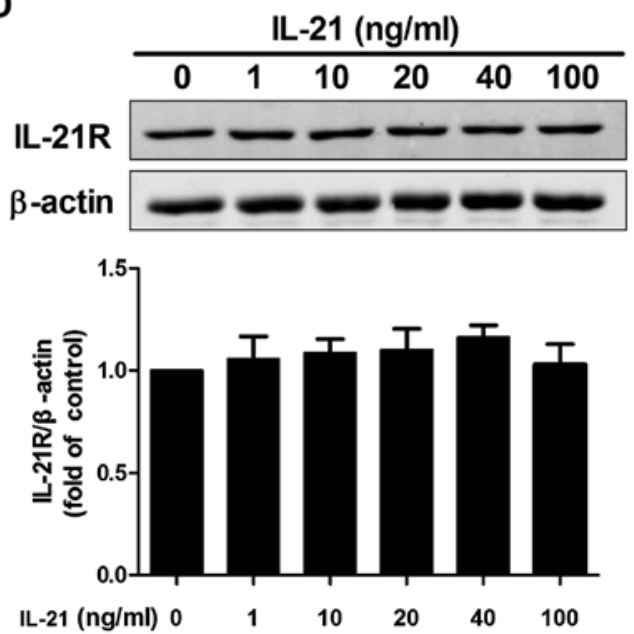

Figure 1. Effect of interleukin-21 (IL-21) on the expression of IL-21 receptor (IL-21R) and receptor activator of nuclear factor- $\kappa$ B (RANK) in RAW264.7 cells. RAW264.7 cells were cultured with various concentrations of IL-21 (0, 1, 10, 20 and $40 \mathrm{ng} / \mathrm{ml})$ for $48 \mathrm{~h}$. (A and C) The mRNA expression of RANK and IL-21R was determined by RT-PCR. (B and D) The protein expression of RANK and IL-21R was determined by western blot analysis. Data are expressed as the means \pm SEM. ${ }^{*} \mathrm{P}<0.05,{ }^{* *} \mathrm{P}<0.01$ vs. control. Three separate experiments were performed with similar results.

of RANKL or RANKL-producing cells, IL-21 enhanced the expression of CTR directly, and the number of multinucleated cells and $\mathrm{CTR}^{+}$osteoclasts was increased. RT-qPCR also verified the increased mRNA expression of CTR and cathepsin $\mathrm{K}$ in the IL-21 group compared with that in the negative group (Fig. 3B).

In order to eliminate the osteoclastogenic effects of endogenous RANKL, OPG was added to the culture system. The results showed that OPG had no effect on IL-21-induced osteoclastogenesis (Fig. 4). The results suggested that the effect of IL-21 on the stimulation of osteoclast differentiation was unaffected by endogenous RANKL.

The scanning electron microscope images showed a number of resorption pits on the bone slices cultured with RANKL. In the IL-21 groups, a few resorption pits were observed (Fig. 5). The results indicated that IL-21 had direct osteoclastogenic potential without the facilitation of RANKL, although the effect was mild.

IL-21 induces osteoclastogenesis of RAW264.7 cells through the PI3K/AKT signaling pathway. IL-21 activates several signaling pathways, including the JAK1 and STAT3 pathway, the mitogen-activated protein kinase (MAPK) pathway, and the PI3K signaling pathway (9). To determine the intracellular mechanisms involved in IL-21-induced osteoclastogenesis, we evaluated the effect of IL-21 on the PI3K/AKT, STAT3 and ERK1/2 pathways. We stimulated RAW264.7 cells with IL-21 (20 ng/ml) for 5, 15, 30, 45, 60, 90 and $120 \mathrm{~min}$. Western blot analysis revealed that (Fig. 6A and B) the phosphorylation of AKT and STAT3 were significantly induced by IL-21. Phosphorylated (p-)AKT was highly activated at 5-15 min after IL-21 (20 ng/ml) stimulation and p-STAT3 levels were increased at 30-60 min of IL-21 stimulation. There was no phosphorylation of ERK.

To examine the intracellular signaling pathways mediating the induction of osteoclast differentiation by IL-21, RAW264.7 cells were pre-treated with the signaling pathway inhibitors AG490 (JAK-2/STAT-3 inhibitor; $50 \mu \mathrm{M}$ ), LY294002 (PI3K/AKT inhibitor; $10 \mu \mathrm{M}$ ), and PD98059 (ERK inhibitor; $20 \mu \mathrm{M}$ ) for $30 \mathrm{~min}$, and then cultured with IL-21 (20 ng/ $\mathrm{ml}$ ) for 5 days. The PI3K/AKT pathway inhibitor LY294002 significantly suppressed IL-21-induced osteoclastogenesis. As shown in Fig. 6C, no $\mathrm{TRAP}^{+}$cells were found in the LY294002 group. No significant differences in the number 
A

M-CSF $5 \mathrm{ng} / \mathrm{ml}$

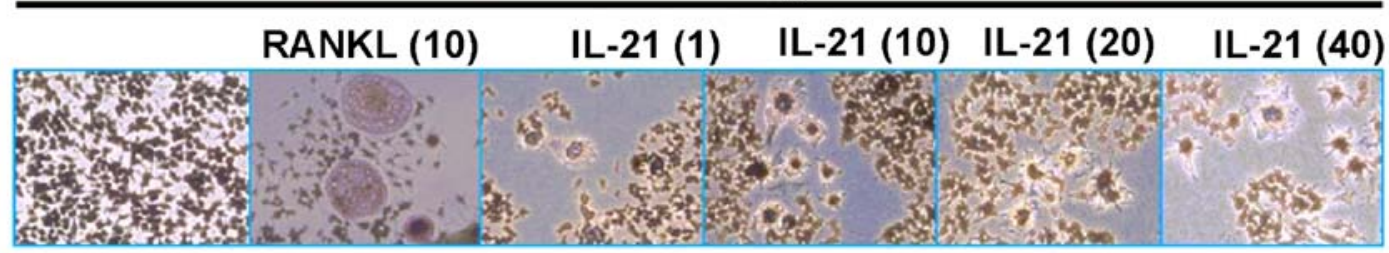

B

M-CSF $5 \mathrm{ng} / \mathrm{ml}$

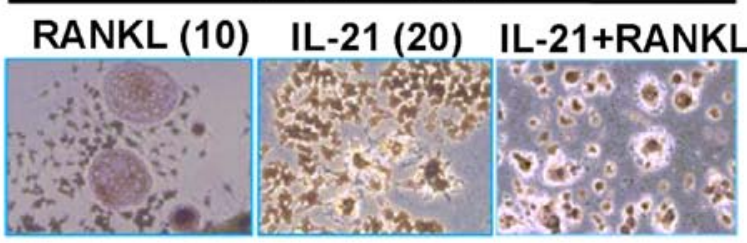

C
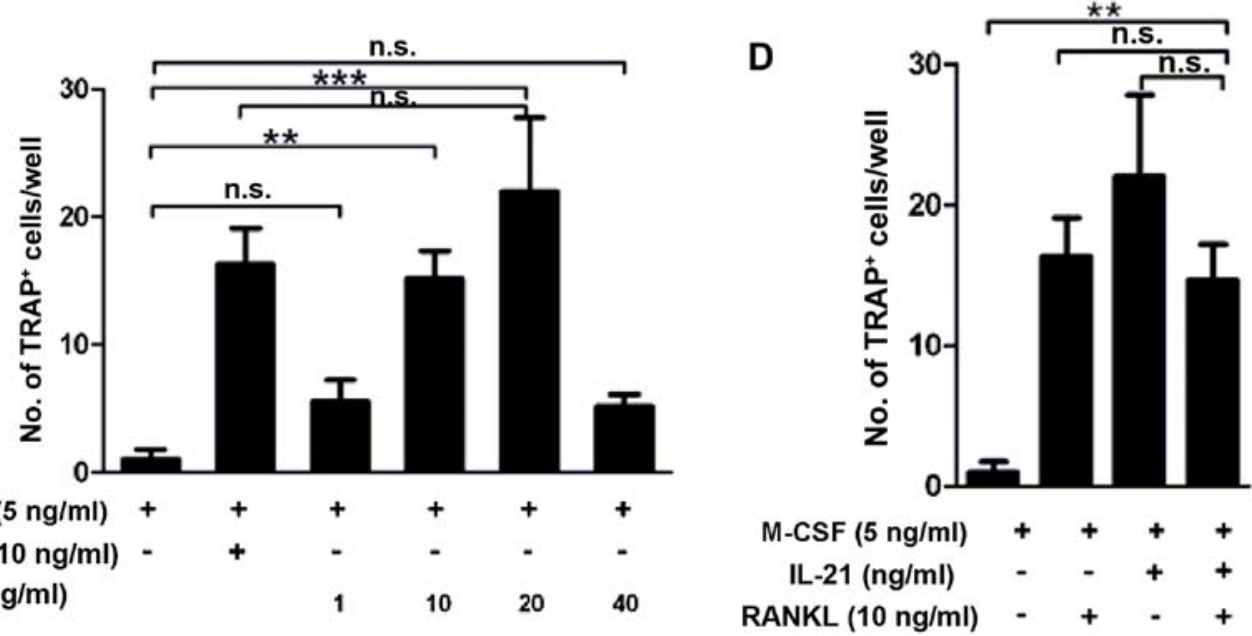

Figure 2.Interleukin-21 (IL-21) induces osteoclastogenesis in RAW264.7 cells. RAW264.7 cells were cultured in 24 -well plates (5x104/well) in the presence of $5 \mathrm{ng} / \mathrm{ml}$ recombinant mouse macrophage colony-stimulating factor (M-CSF), with or without soluble receptor activator of nuclear factor- $\kappa \mathrm{B}$ ligand (sRANKL) (10 ng/ml), or various concentrations of IL-21 $(0,1,10,20$ and $40 \mathrm{ng} / \mathrm{ml})$ for 5 days. (A-D) Tartrate-resistant acid phosphatase (TRAP) staining was performed to evaluate the formation of osteoclasts. (A and C) Number of TRAP-positive osteoclasts at various concentrations of IL-21, and (B and D) in the presence or absence of RANKL. Original magnification, $x 100$. Data are expressed as the means \pm SEM of three samples. ${ }^{* *} \mathrm{P}<0.01,{ }^{* * * *} \mathrm{P}<0.001$ vs. control.

of TRAP $^{+}$cells were observed among the IL-21+AG490 $(11.33 \pm 7.11 /$ well, $\mathrm{P}>0.05)$, IL-21+PD98059 (8.33 $\pm 2.02 /$ well, $\mathrm{P}>0.05)$, and IL-21 (20 ng/ml) groups. The mRNA expression of CTR, TRAP and cathepsin $\mathrm{K}$ were also decreased in the LY294002 group (Fig. 7A and B). The RAW264.7 cells were pre-treated with signaling pathway inhibitors (AG490 $50 \mu \mathrm{M}$, LY294002 $10 \mu \mathrm{M}$ and PD98059 $20 \mu \mathrm{M}$ ) for $30 \mathrm{~min}$ prior to adding IL-21. RANK expression was significantly inhibited by the PI3K/AKT signal pathway inhibitor LY294002 (Fig. 7C). These results showed that IL-21 may promote osteoclastogenesis through the PI3K/AKT signaling pathway.

Osteoclastogenesis is induced by IL-21 in RA. PBMCs obtained from patients with RA were cultured with IL-21 to induce osteoclastogenesis. IL-21 induced osteoclast formation in the PBMCs isolated from patients with RA, showing similar results to the cell line (Fig. 8A). With the existence of $\mathrm{T}$ cells in the culture, IL-21 induced more $\mathrm{TRAP}^{+}$cells in the $10 \mathrm{ng} / \mathrm{ml}$ group $(10 \pm 4.97 /$ well, $\mathrm{P}=0.019)$ and $50 \mathrm{ng} / \mathrm{ml}$ group $(21 \pm 8.46 /$ well, $\mathrm{P}<0.01)$ than the negative control (0.8 $\pm 0.57 /$ well) (Fig. $8 \mathrm{~A})$. Without RANKL-providing
T cells, IL-21 $50 \mathrm{ng} / \mathrm{ml}(14.38 \pm 3.22 /$ well, $\mathrm{P}<0.01)$ also showed osteoclastogenic activity, compared with negative control group (1.38 $\pm 1.03 /$ well) (Fig. 8C). IL-21 did not enhance the osteoclastogenic effect of RANKL (Fig. 8B and D).

\section{Discussion}

IL-21 is a four-helix-bundle cytokine produced by activated $\mathrm{CD}^{+}{ }^{+} \mathrm{T}$ cells, activated natural killer $\mathrm{T}$ cells and Tfh cells. IL-21 binds to the cell surface receptor IL-21R, a member of the class I cytokine receptor family, specifically to the $\gamma c$ subunit which is shared with IL-2, IL-4, IL-7, IL-9, IL-13 and IL-15 receptors (15), leading to the activation of members of the JAK family of protein tyrosine kinases and STAT molecules. In some cell types, IL-21 also activates members of the MAPK family (16). In addition, IL-21R signaling may also lead to activation of both the MAPK and PI3K pathways, which are important for IL-21-mediated cell proliferation (17). IL-21 may play important roles in regulating the function of multiple types of immune and non-immune cells. 
A
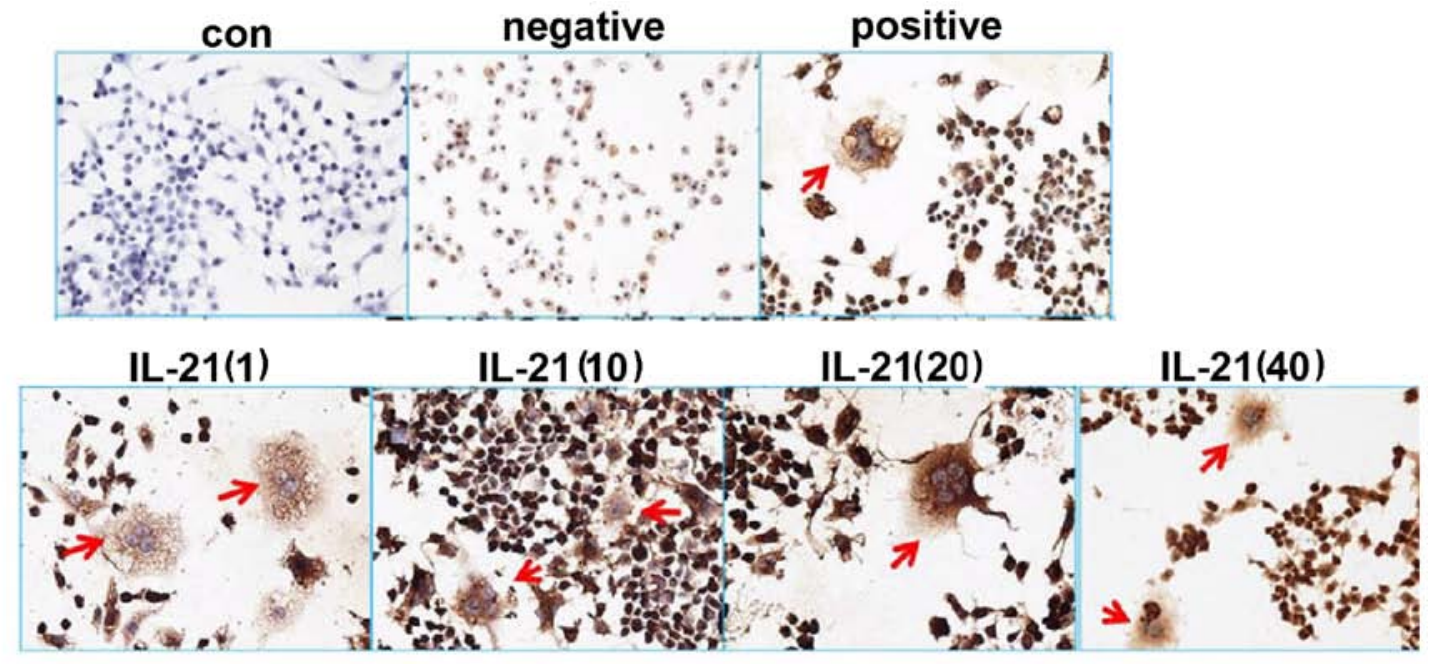

B
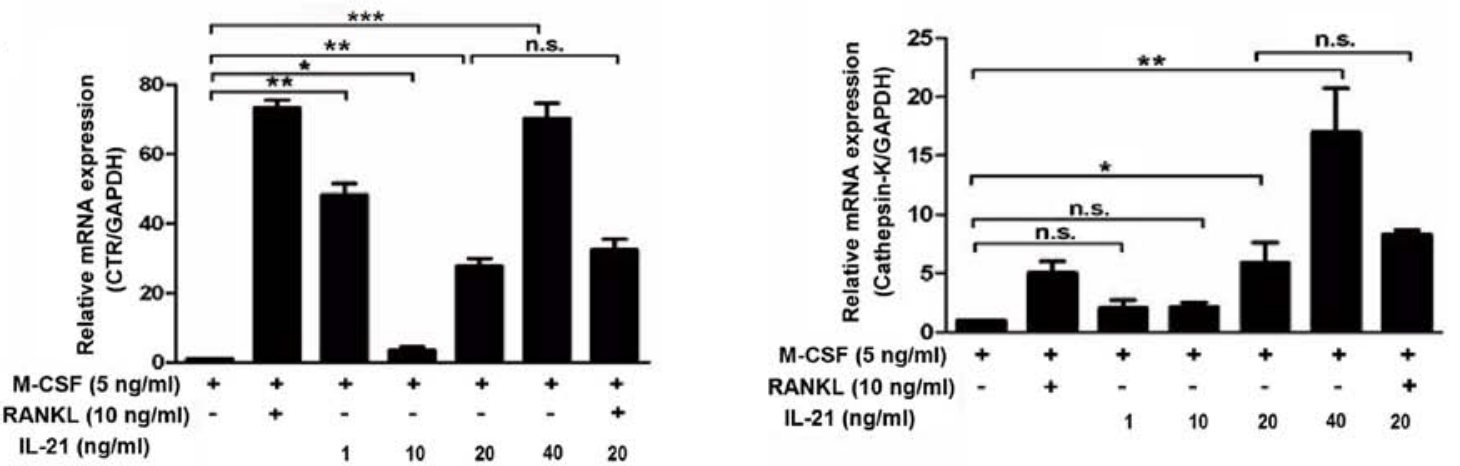

C

\begin{tabular}{|c|c|c|c|c|c|c|}
\hline M-CSF & + & + & + & + & + & + \\
\hline RANKL & - & + & - & - & - & - \\
\hline IL-21 & $\cdot$ & - & 1 & 10 & 20 & 40 \\
\hline CTR & 3 & & nes & rent & 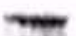 & 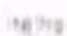 \\
\hline
\end{tabular}

$\beta$-actin
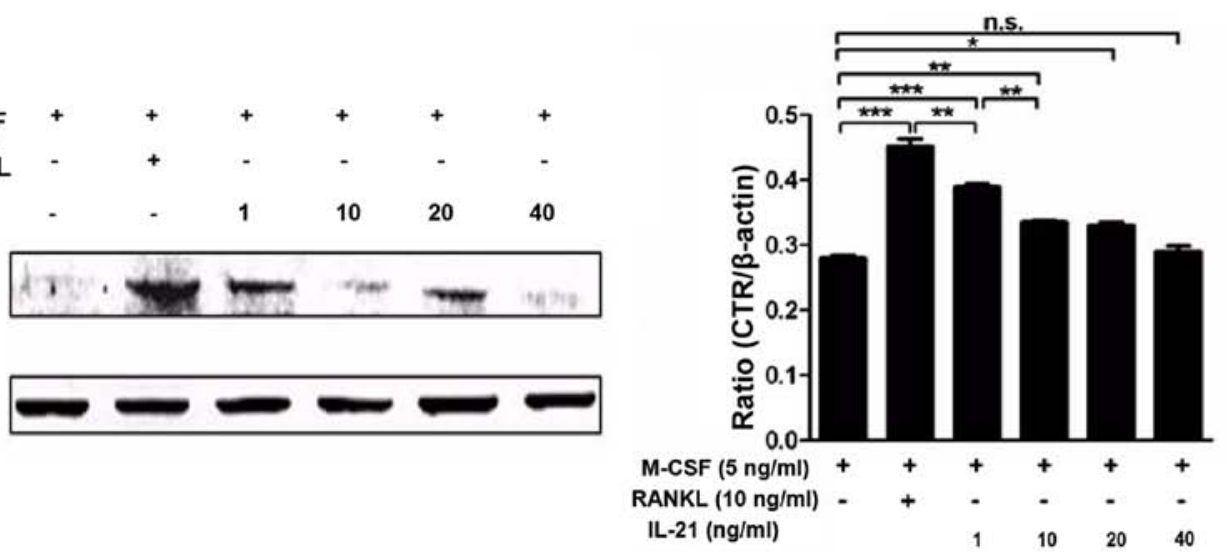

Figure 3. Interleukin-21 (IL-21) enhances calcitonin receptor (CTR) and cathepsin K expression in RAW264.7 cells. RAW264.7 cells were cultured in 24-well plates $\left(5 \times 10^{4} /\right.$ well) in the presence of $5 \mathrm{ng} / \mathrm{ml}$ recombinant mouse macrophage colony-stimulating factor (M-CSF), with or without soluble receptor activator of nuclear factor- $\mathrm{kB}$ ligand (sRANKL) $(10 \mathrm{ng} / \mathrm{ml})$, or various concentrations of IL-21 $(0,1,10,20$ and $40 \mathrm{ng} / \mathrm{ml})$ for 5 days. (A) Immunocytochemistry revealed the positive expression of CTR in the IL-21 group. The red arrows show multinucleated CTR-positive osteoclasts. (B) CTR and cathepsin K expression were detected by RT-qPCR. (C) The protein expression of CTR was detected by western blot analysis. Original magnification, $\mathrm{x} 100$. Data are expressed as the means \pm SEM of three samples. ${ }^{*} \mathrm{P}<0.05,{ }^{* * *} \mathrm{P}<0.01,{ }^{* * *} \mathrm{P}<0.001$.

IL-21 driven tissue damage has been demonstrated in some $\mathrm{T}$ cell-mediated diseases, including RA. IL-21 was demonstrated to participate in $\mathrm{T}$ cell activation and synovial inflammation in RA (8). Young et al demonstrated that the blockade of IL-21 with IL-21R.Fc ameliorated clinical disease activity in animal models of CIA (12). Blocking IL-21 by IL-21R.Fc effectively ameliorated CIA by suppressing Th17 and antibody production (18). IL-21R-deficiency protects against severe inflammation and joint destruction in antigen-induced arthritis and chronic streptococcal cell wallinduced arthritis (19). Kwok et al found that IL-21 enhanced in vitro osteoclastogenesis by inducing RANKL expression in $\mathrm{CD}^{+} \mathrm{T}$ cells and FLSs (13). The results indicate that IL-21 may also be involved in the bone erosion associated with RA. Whether IL-21 has a direct osteolastogenic role remains to be clarified.

In this study, we demonstrated that IL-21 promoted osteoclastogenesis in RAW264.7 cells in the absence of 

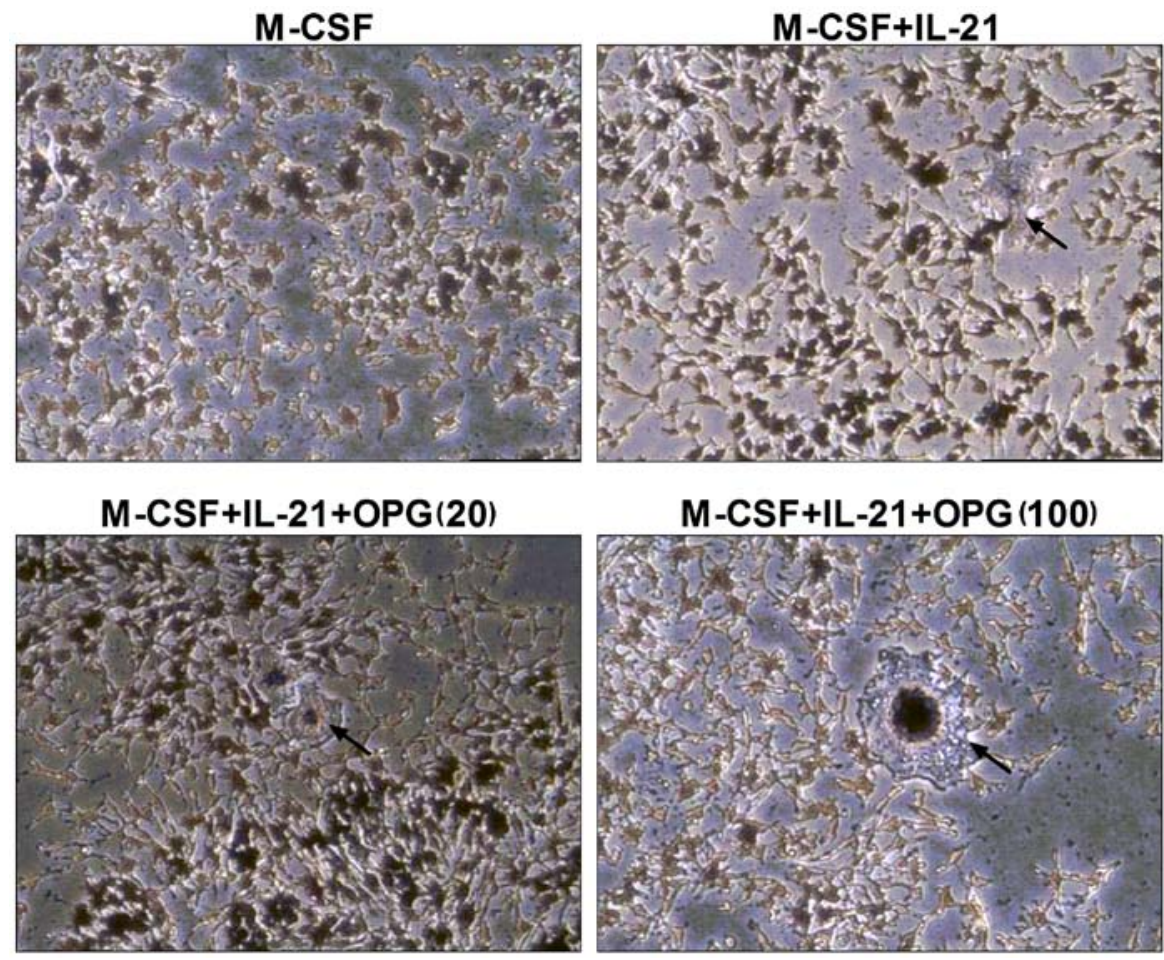

Figure 4. Effect of osteoprotegerin (OPG) on interleukin-21 (IL-21)-induced osteoclastogenesis in RAW264.7 cells. OPG (20 and $100 \mathrm{ng} / \mathrm{ml})$ was added to the culture to eliminate the osteoclastogenic effects of endogenous receptor activator of nuclear factor- $\mathrm{KB}$ ligand (RANKL). OPG had no effect on IL-21-induced osteoclastogenesis. The black arrows show TRAP-positive osteoclasts. Original magnification, x100.

A
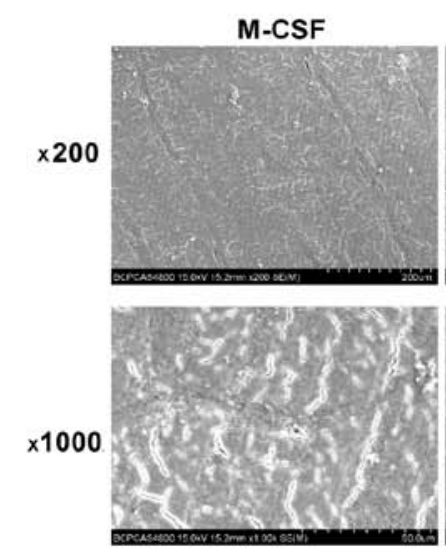

M-CSF+RANKL
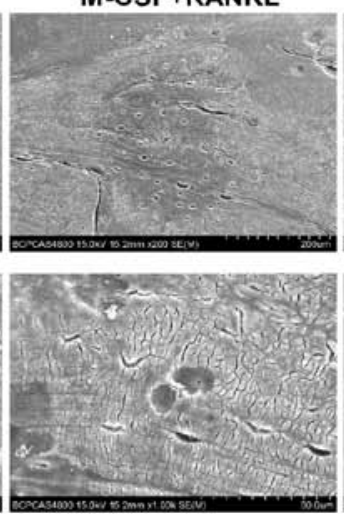

$M-C S F+I L-21$
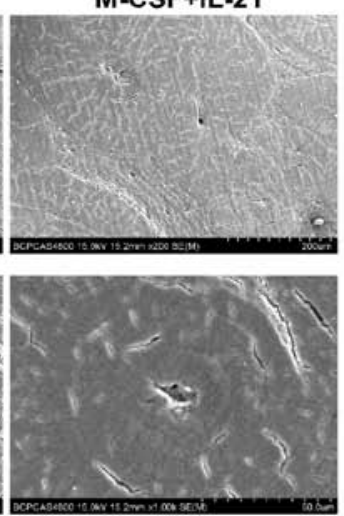

B

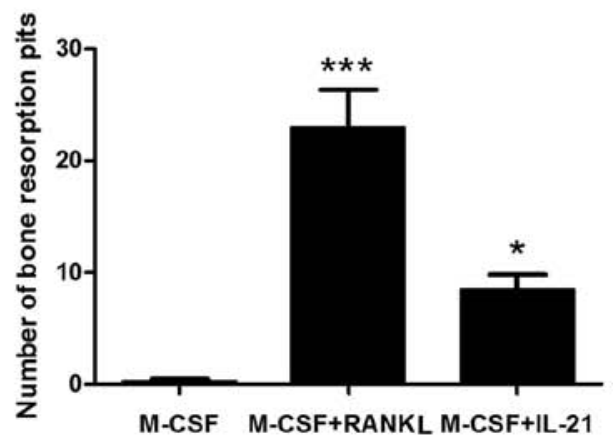

Figure 5. Scanning electron microscope images of interleukin-21 (IL-21)-induced formation of bone resorption pits. (A) RAW264.7 cells were cultured in 96-well plates with thin slices of cow femoral bone in the presence of macrophage colony-stimulating factor (M-CSF; $5 \mathrm{ng} / \mathrm{ml}$ ) with or without receptor activator of nuclear factor- $\mathrm{kB}$ ligand (RANKL) $(10 \mathrm{ng} / \mathrm{ml})$ or IL-21 $(20 \mathrm{ng} / \mathrm{ml})$. After culturing for 7 days, the resorption pits on the bone slices were observed under a scanning electronic microscope. (B) Statistical results of (A). Data are expressed as the means \pm SEM of three samples. ${ }^{*} \mathrm{P}<0.05,{ }^{* * * *} \mathrm{P}<0.001$ vs. M-CSF group..

RANKL. IL-21 promoted osteoclast formation as demonstrated by increased numbers of TRAP-positive cells and increased CTR protein expression. Bone resorption analysis showed the presence of resorption pits in the IL-21 group, although the numbers of resorption pits was fewer than those of the RANKL group. These findings suggest that IL-21 has direct osteoclastogenic potential in the absence of RANKL, although IL-21 is not as potent as RANKL. The findings of the present study showed that IL-21 promotes osteoclastogenesis in the PBMCs isolated from patients with RA in the presence or absence of RANKL-providing $\mathrm{T}$ cells. These results indicate that IL-21 may induce osteoclastogenesis directly in RA.

Our results were different from those of previous studies reported by Kwok et al (13). They found that IL-21 alone did not promote osteoclastogenesis; it markedly potentiated osteoclastogenesis in the presence of RANKL and M-CSF, both in the mouse and human samples. This effect was mediated by the JAK/STAT3 signaling pathway (13). By contrast, in the present study, we demonstrated that IL-21 induced osteoclastogenesis in RAW264.7 cells directly. To further clarify the mechanism responsible for the induction of 
A

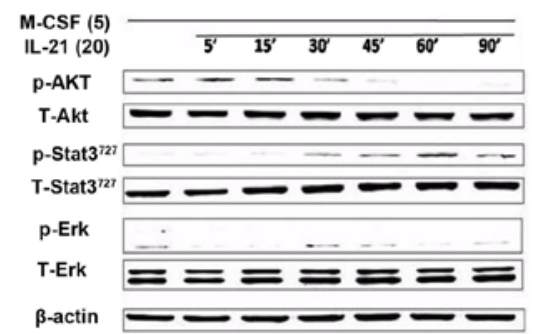

B
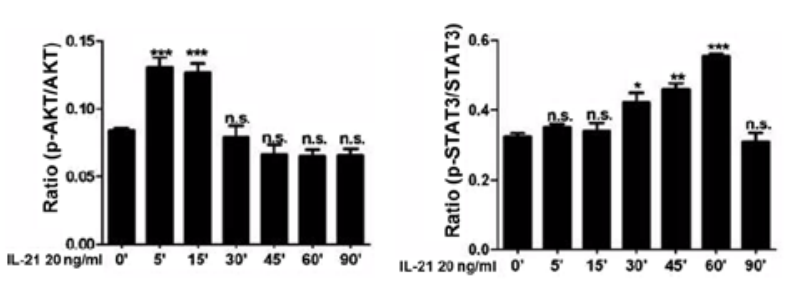

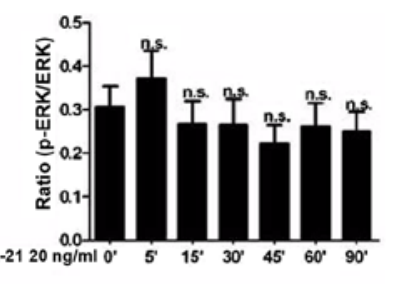

C
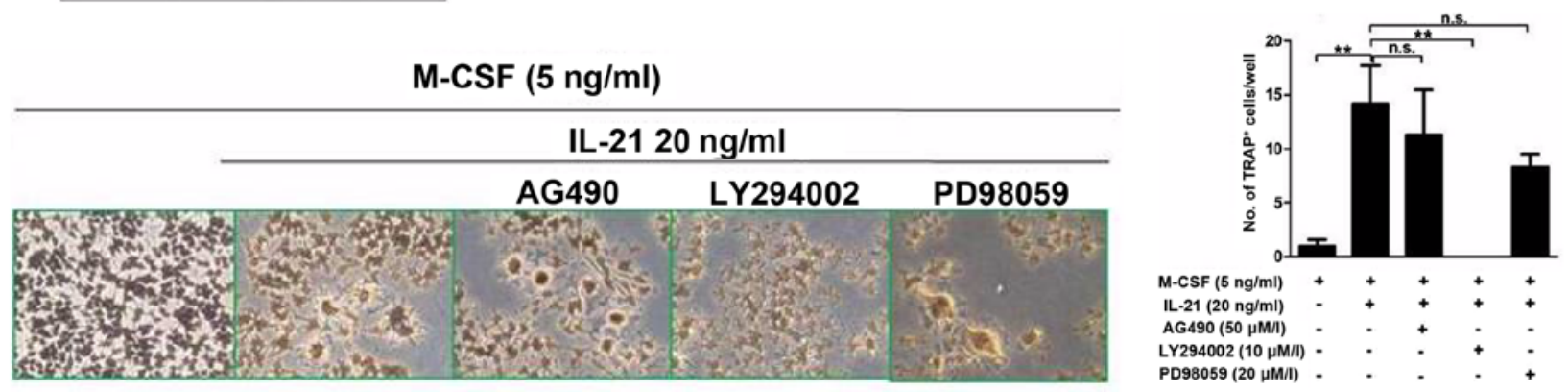

Figure 6. Interleukin-21 (IL-21) promotes osteoclastogenesis in RAW264.7 cells through the PI3K/AKT signaling pathway. (A) The phosphorylation of AKT, STAT3 and ERK were examined by western blot analysis. RAW264.7 cells were stimulated with IL-21 (20 ng/ml) for the indicated times in the presence of $5 \mathrm{ng} / \mathrm{ml}$ macrophage colony-stimulating factor (M-CSF), and cells were harvested for western blot analysis. (B) Statistical results of (A). (C) The effect of inhibiting STAT3, ERK1/2 and PI3K/AKT signaling pathways on IL-21-induced osteoclastogenesis. RAW264.7 cells were incubated with specific pathways inhibitors [ERK1/2 pathway inhibitor PD98059 $(20 \mu \mathrm{M})$, PI3K/AKT inhibitor LY294002 $(10 \mu \mathrm{M})$ and STAT3 pathway inhibitor AG490 (50 $\mu \mathrm{M})$ ] for 30 min prior to stimulation with IL-21 $(20 \mathrm{ng} / \mathrm{ml})$. Osteoclast formation was determined using tartrate-resistant acid phosphatase (TRAP) staining after 5 days of culture. Original magnification, $x 100$. Data are expressed as the means \pm SEM of three samples. ${ }^{*} \mathrm{P}<0.05,{ }^{* *} \mathrm{P}<0.01,{ }^{* * * *} \mathrm{P}<0.001$ vs. control or as shown in figure.

A

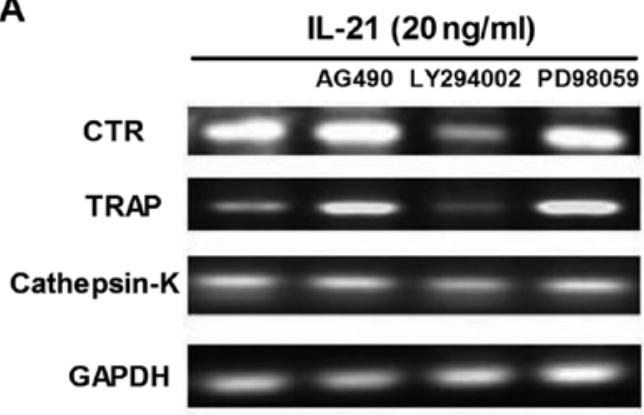

C

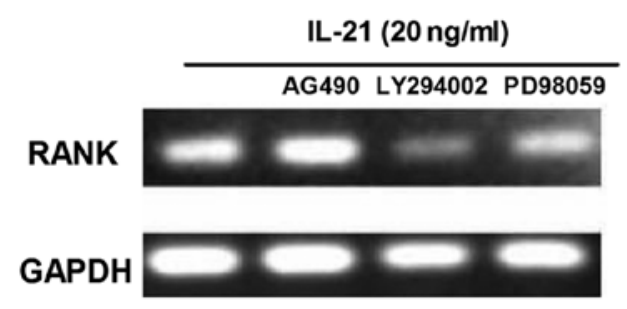

B
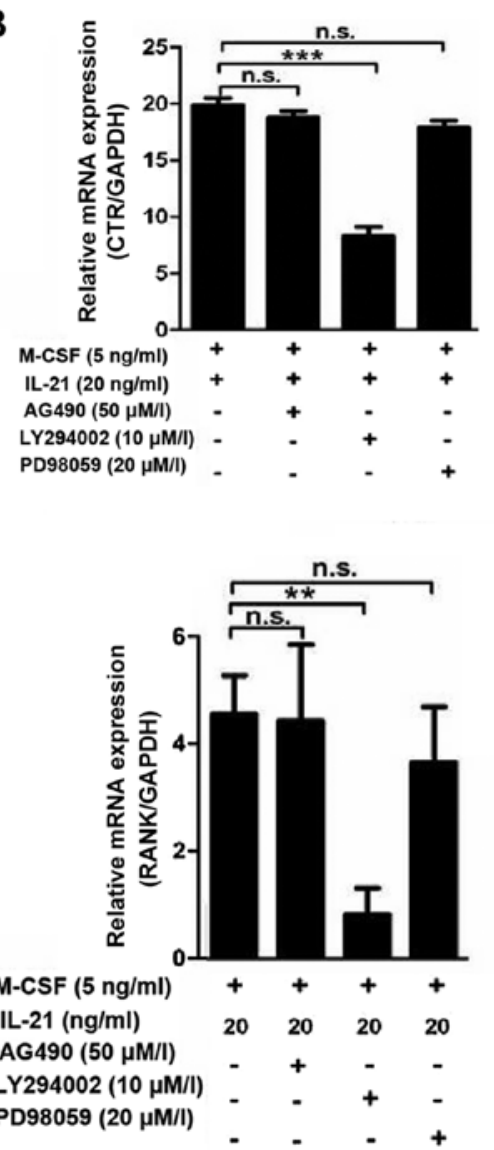

Figure 7. Effect of signaling pathway inhibitors on the expression of osteoclasts markers induced by interleukin-21 (IL-21). RAW264.7 cells were incubated with specific pathways inhibitors (AG490, LY294002 and PD98059) for 30 min prior to stimulation with IL-21 (20 ng/ml). (A and B) RT-PCR results of calcitonin receptor (CTR), cathepsin K and tartrate-resistant acid phosphatase (TRAP) expression. (C) RT-qPCR results of RANK expression. Data are expressed as the means \pm SEM of three samples. ${ }^{* *} \mathrm{P}<0.01,{ }^{* * *} \mathrm{P}<0.001$. 
A

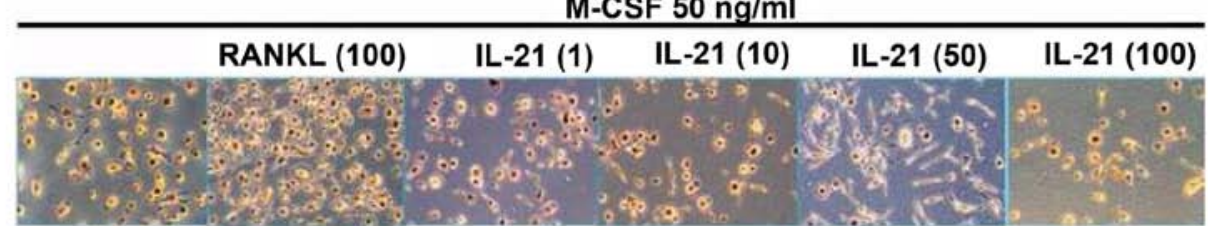

B

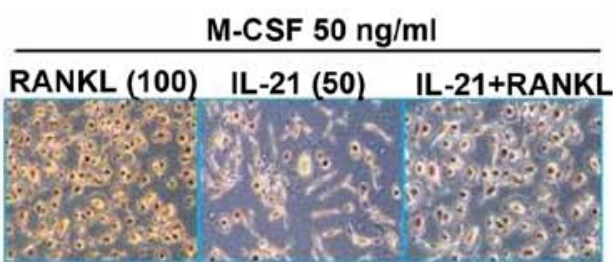

C

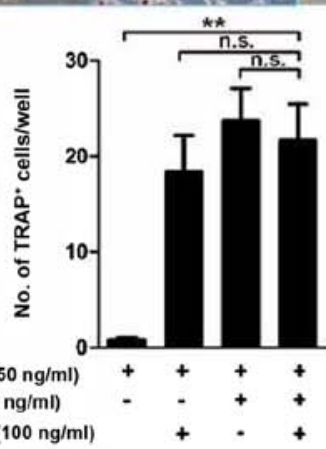

M-CSF $50 \mathrm{ng} / \mathrm{ml}$

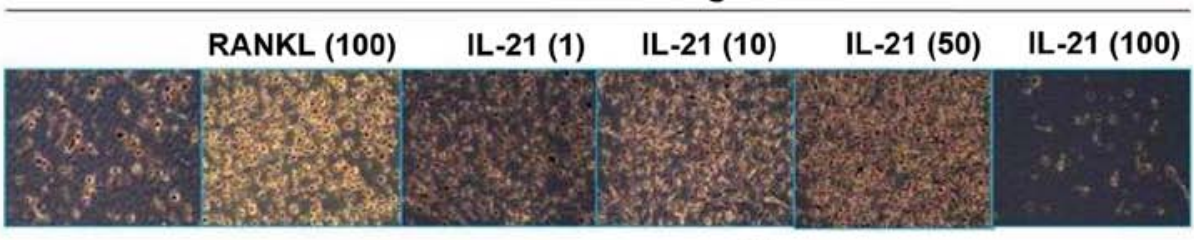

D

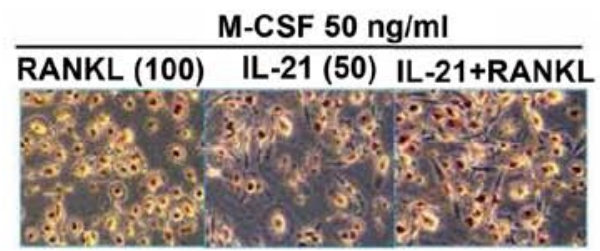

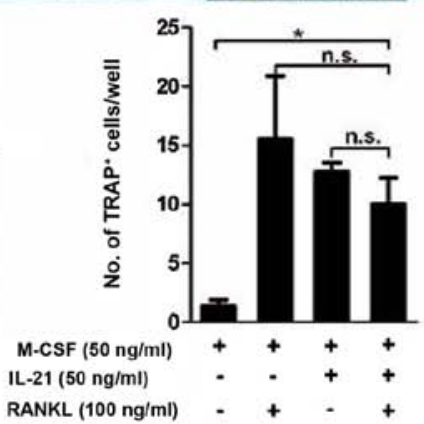
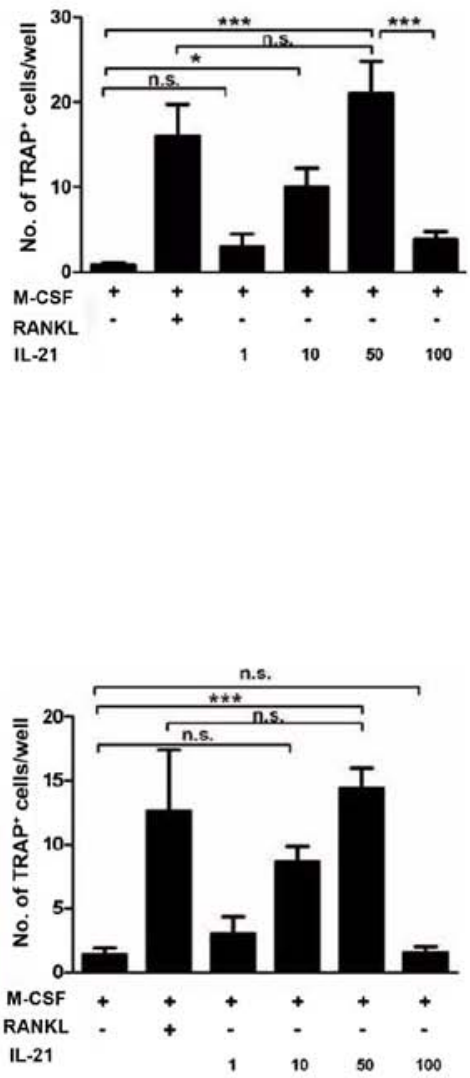

Figure 8. Osteoclastogenesis is induced by interleukin-21 (IL-21) in peripheral blood mononuclear cells (PBMCs) isolated from patients with rheumatoid arthritis (RA). (A) PBMCs obtained from patients with RA were cultured in 24-well plates at a density of $1 \times 10^{6}$ cells/well in the presence of T cells, and then macrophage colony-stimulating factor (M-CSF) $(50 \mathrm{ng} / \mathrm{ml}), \mathrm{M}-\mathrm{CSF}+$ receptor activator of nuclear factor- $\mathrm{KB}$ ligand (RANKL) (100 ng/ml), or IL-21 (1, 10 , 50 and $100 \mathrm{ng} / \mathrm{ml}$ ) were added for 7 days in order to generate osteoclasts. Tartrate-resistant acid phosphatase (TRAP)-positive cells were identified using an acid phosphatase kit. (B) PBMCs were co-cultured with T cells in the presence of M-CSF (50 ng/ml), M-CSF + RANKL (100 ng/ml), or IL-21 (50 ng/ml) for 7 days. TRAP-positive cells were identified using an acid phosphatase kit. (C) PBMCs were cultured with M-CSF (50 ng/ml), M-CSF + RANKL (100 ng/ml), or IL-21 (1, 10, 50 and $100 \mathrm{ng} / \mathrm{ml})$ for 7 days. TRAP-positive cells were identified using an acid phosphatase kit. (D) PBMCs were cultured with M-CSF $(50 \mathrm{ng} / \mathrm{ml}), \mathrm{M}-\mathrm{CSF}+\mathrm{RANKL}(100 \mathrm{ng} / \mathrm{ml})$, or IL-21 $(50 \mathrm{ng} / \mathrm{ml})$ for 7 days. TRAP-positive cells were identified using an acid phosphatase kit. Original magnification, $x 100$. Data are expressed as the means \pm SEM of three samples. ${ }^{*} \mathrm{P}<0.05,{ }^{* *} \mathrm{P}<0.01,{ }^{* * * *} \mathrm{P}<0.001$.

osteoclastogenesis by IL-21, RAW264.7 cells were pre-treated with various signaling pathway inhibitors prior to culture with IL-21. The results of this experiment showed that IL-21 activated the JAK/STAT3 and PI3K/AKT signaling pathways in RAW264.7 cells. The PI3K/AKT pathway inhibitor LY294002 significantly suppressed IL-21-induced osteoclastogenesis, showing no TRAP-positive cells, and the decreased expression of osteoclast markers including TRAP and cathepsin K. Thus, these findings suggest that IL-21 may promote osteoclastogenesis through the PI3K/AKT signaling pathway rather than the JAK/STAT3 signaling pathway. Notably, although IL-21 stimulated RANK expression in RAW264.7 cells, it did not enhance the osteoclastogenic potential of RANKL. The interaction between IL-21 and RANKL in inducing osteoclastogenesis remains to be studied further.
The limitation of the present study is that RAW264.7 cells cannot represent the macrophages of RA patients. For this reason, further studies regarding the role of IL-21 in osteoclastogenesis and bone erosion in patients with RA are warranted.

In conclusion, the findings of the present study demonstrate that IL-21 promotes osteoclastogenesis in RAW264.7 cells as well as in PBMCs isolated from patients with RA in the absence of RANKL or RANKL-providing T cells. Thus, therapy targeting IL-21 may be of value in preventing bone erosions in patients with RA.

\section{Acknowledgements}

The present study was supported by the National Natural Science Foundation of China (nos. 81102255, 81273293 and 81571573). 


\section{References}

1. Maruotti N, Grano M, Colucci S, d'Onofrio F and Cantatore FP: Osteoclastogenesis and arthritis. Clin Exp Med 11: 137-145, 2011.

2. Branimir A and Miroslav M: Pathogenesis of rheumatoid arthritis. Reumatizam 61: 19-23, 2014 (In Croatian)

3. Kawai VK, Stein CM, Perrien DS and Griffin MR: Effects of anti-tumor necrosis factor $\alpha$ agents on bone. Curr Opin Rheumatol 24: 576-585, 2012.

4. Bloemen V, Schoenmaker T, de Vries TJ and Everts V: IL-1 $\beta$ favors osteoclastogenesis via supporting human periodontal ligament fibroblasts. J Cell Biochem 112: 1890-1897, 2011.

5. Parrish-Novak J, Dillon SR, Nelson A, Hammond A Sprecher C, Gross JA, Johnston J, Madden K, Xu W, West $\mathbf{J}$, et al: Interleukin 21 and its receptor are involved in NK cell expansion and regulation of lymphocyte function. Nature 408: 57-63, 2000.

6. Leonard WJ and Spolski R: Interleukin-21: a modulator of lymphoid proliferation, apoptosis and differentiation. Nat Rev Immunol 5: 688-698, 2005.

7. Di Fusco D, Izzo R, Figliuzzi MM, Pallone F and Monteleone G: IL-21 as a therapeutic target in inflammatory disorders. Expert Opin Ther Targets 18: 1329-1338, 2014.

8. Li J, Shen W, Kong K and Liu Z: Interleukin-21 induces T-cell activation and proinflammatory cytokine secretion in rheumatoid arthritis. Scand J Immunol 64: 515-522, 2006.

9. Spolski R and Leonard WJ: Interleukin-21: A double-edged sword with therapeutic potential. Nat Rev Drug Discov 13: 379-395, 2014

10. Monteleone G, Caruso R, Fina D, Peluso I, Gioia V, Stolfi C, Fantini MC, Caprioli F, Tersigni R, Alessandroni L, et al: Control of matrix metalloproteinase production in human intestinal fibroblasts by interleukin 21. Gut 55: 1774-1780, 2006.

11. Rasmussen TK, Andersen T, Hvid M, Hetland ML, Hørslev-Petersen K, Stengaard-Pedersen K, Holm CK and Deleuran B: Increased interleukin 21 (IL-21) and IL-23 are associated with increased disease activity and with radiographic status in patients with early rheumatoid arthritis. J Rheumatol 37 2014-2020, 2010.
12. Young DA, Hegen M, Ma HL, Whitters MJ, Albert LM, Lowe L, Senices M, Wu PW, Sibley B, Leathurby Y, et al: Blockade of the interleukin-21/interleukin-21 receptor pathway ameliorates disease in animal models of rheumatoid arthritis. Arthritis Rheum 56: 1152-1163, 2007.

13. Kwok SK, Cho ML, Park MK, Oh HJ, Park JS, Her YM, Lee SY, Youn J, Ju JH, Park KS, et al: Interleukin-21 promotes osteoclastogenesis in humans with rheumatoid arthritis and in mice with collagen-induced arthritis. Arthritis Rheum 64: 740-751, 2012.

14. Kong YY, Yoshida H, Sarosi I, Tan HL, Timms E, Capparelli C, Morony S, Oliveira-dos-Santos AJ, Van G, Itie A, et al: OPGL is a key regulator of osteoclastogenesis, lymphocyte development and lymph-node organogenesis. Nature 397: 315-323, 1999.

15. Parrish-Novak J, Foster DC, Holly RD and Clegg $\mathrm{CH}$ : Interleukin-21 and the IL-21 receptor: novel effectors of NK and T cell responses. J Leukoc Biol 72: 856-863, 2002.

16. Spolski R and Leonard WJ: The Yin and Yang of interleukin-2 in allergy, autoimmunity and cancer. Curr Opin Immunol 20: 295-301, 2008.

17. Zeng R, Spolski R, Casas E, Zhu W, Levy DE and Leonard WJ: The molecular basis of IL-21-mediated proliferation. Blood 109: 4135-4142, 2007.

18. Ryu JG, Lee J, Kim EK, Seo HB, Park JS, Lee SY, Moon YM, Yoo SH, Park YW, Park SH, et al: Treatment of IL-21R-Fc control autoimmune arthritis via suppression of STAT3 signal pathway mediated regulation of the Th17/Treg balance and plasma B cells. Immunol Lett 163: 143-150, 2015.

19. Marijnissen RJ, Roeleveld DM, Young D, Nickerson-Nutter C, Abdollahi-Roodsaz S, Garcia de Aquino S, van de Loo FA, van Spriel AB, Boots AM, van den Berg WB and Koenders MI: Interleukin-21 receptor deficiency increases the initial toll-like receptor 2 response but protects against joint pathology by reducing Th1 and Th17 cells during streptococcal cell wall arthritis. Arthritis Rheumatol 66: 886-895, 2014. 